\title{
Reasons behind Aversion from Reading by the Students of the Faculty of Educational Sciences at Tafila Technical University
}

\author{
Ruba Al-Mahasneh \\ Assistant Professor, Faculty of Educational Sciences \\ Tafila Technical University, Jordan \\ E-mail: Mashhad33@gmail.com
}

\begin{abstract}
Asma' Al-Zreqat
Assistant Professor, Faculty of Arts, Tafila Technical University, Jordan E-mail: dr.asmaalzregat@yahoo.com
\end{abstract}

\author{
Montaha Al-Hraishat \\ Lecturer, Faculty of Education \\ Tafila Technical University, Jordan \\ E-mail: alhraishat_m@yahoo.com
}

Received: March 2, 2017

Accepted: May 9, 2017 Published: May 31, 2017

doi:10.5296/jse.v7i2.11229

URL: https://doi.org/10.5296/jse.v7i2.11229

\begin{abstract}
The study aimed at identifying the reasons behind aversion from reading by the students of the Faculty of Educational Sciences at Tafila Technical University in relation to the variables of gender and major. To achieve the aims of the study, a questionnaire was constructed. The questionnaire consisted of (45) items; each one represents a reason behind students' aversion from reading. The questionnaire was administered on a random sample comprising (201) male and female students enrolled in the Faculty of Educational Sciences at Tafila Technical University during the second semester of the academic year 2015/2016.
\end{abstract}




\section{Macrothink}

Journal of Studies in Education

ISSN 2162-6952

2017, Vol. 7, No. 2

The results revealed that the degree of the samples' ratings of the reasons behind aversion from reading on the tool as a whole was medium, the main reasons behind aversion from reading by the students of the Faculty of Educational Sciences were electronic addiction and students' tendencies towards having the information which is easy to reach instead of looking for it, and there were no statistically significant differences at level $(\alpha=0.05)$ attributed to the variables of gender and major.

Key words: reading, aversion from reading, electronic addiction. 


\section{Introduction}

Reading is one of the most important means of knowledge and communications. It is also a crucial process that allows for the intake, distribution, and activation of ideas, as well as the development of mental and creative thinking skills. Therefore, reading is one of the most important means to attain knowledge. It is the greatest aid in the communication process, as it expresses the history, present, and future of human existence. Moreover, it has an undeniable effect on the formation and components of one's personality and character.

Maybe another indication of the importance of reading in our lives is its great impact on the establishment of civilizations, especially modern ones, which value readings as a window to human thought. (Reading becomes an original habit in the hearts of the readers urging them to exploit every minute to read, educate themselves, and increase their knowledge and ability to perceive and read ideas and emotions. Avid readers also become excited to fill their free time with reading about all forms of knowledge to gather a mental wealth that can enrich their feelings and sensation. Hence, the first mission of elementary schools is to install the passion for reading in the hearts of students. This passion will gradually grow making reading a priority for the generation, an activity they attend voluntarily, making them a source of pride to the school) (Adas, 2005, p15).

We can safely say that nobody can do without reading in any community. It is a tool that enables people to obtain ideas, information, knowledge necessary for self-development, problem solving, and adaptation with the local community. However, it can be noticed today that students do not read books, magazines, novels, or stories, i.e. they do not do any extracurricular reading. This means that students are not interested in educating themselves. They refrain from reading and do not feel inclined to read books or magazines, because they rely on electronic means, like the internet, as tools of fast research.

Therefore, this study has been designed to investigate the reasons behind the students' aversion from free reading by answering the following questions:

What are the reasons behind aversion from free reading by the students of the faculty of educational sciences at Tafila Technical University who are studying in the second semester of the academic year 2015/2016?

Does the degree of the sample's ratings of the reasons behind aversion from free reading of the students of the faculty of educational sciences at Tafila Technical University who are studying in the second semester of the academic year 2015/2016 vary according to the study's variables: gender (male and female) and major (class teacher and special education)?

\section{Significance of the study}

The significance of the study lies in the following:

The importance of the addressed subject, since reading is the food of thought that helps nations and civilizations to rise and flourish.

The importance of the study's target group: University students, who should be investing 
their spare time by developing their abilities, gaining new knowledge, and releasing their creativity.

Discover the reasons behind the students' aversion from reading to address the issue and come up with valid solutions.

Provide the library and researchers with a reference study that examines the reality of reading for university students, and opens some space for further studies in light of other variables, especially that a thorough scrutiny of previous literature reveals the scarcity of studies that address the aversion from free reading in Jordanian schools and universities.

\section{Limitations of the study}

The population of the study is limited to the students of Tafila Technical University, faculty of educational sciences, who are studying in the academic year 2015/2016.

- The population of the study includes the students of the faculty of educational sciences with all its departments, except postgraduate students and diploma students who study in Tafila Technical University.

- Anything related to university curriculum, e.g. books, summaries, exam material, etc. is excluded from the concept of reading.

- The results of the study depend on the students' level of response and answers to the items of the study's instrument.

\section{Theoretical framework and literature review}

Reading is a cognitive, mental process wherein the visual image is turned into spoken words and sounds, in addition to the comprehension of said words and sounds (Awartani, 2009, p 215). This means that reading is a process that relies on extracting meaning from written and typed words. This is a crucial step of learning and teaching, which enables us to construct things, discover others, expand our knowledge, develop our thoughts, and enjoy the stories and novels we read.

Reading is an art and a skill relies on two main processes:

1. A mechanical process: is the reader's visual recognition of words and sentences known as "the space of recognition", which means the range that the eye can see words and sentences in a single line, as well as the quantity of words an eye can capture in a moment.

2. A mental process: is represented in the brains recognition of the written words and symbols. The meaning of such written material depends on several variables, including the reader's experience in reading, the nature of the material, the material's level of difficulty, the context, and the environment (Abdul Bari, 2009, p.22)

Reading is an important means to gain knowledge and establish direct communication with human knowledge and minds and thoughts of other people. Free reading is one of the main and important pillars of education, teaching, and learning, which plays a complementary to the role of school. Therefore, it's the basis of any educational process and the key to all study 
subjects. And maybe failure in some study subjects or life itself can be attributed to academic weakness in reading, since it provides the individual with ideas and information and opens a window into human heritage and thought. It is also a great resource of general culture, manners, and information about self-development and problem solving skills. In addition, reading increases an individual level of understanding of social issues, entice the spirit of criticism, and provide opportunities for fun and enjoyment. (Lafi, 2006, p. 13)

Reading has numerous, noble goals that elevate the status of individuals and

societies. Reading can contribute to the creation of an aware, cultured society. It can also promote the style, talents, and abilities of an individual, develop his intellectual, linguistic, and expressive capacities, expand his mental and cognitive perceptions through continuous reading, enrich the experiences of upcoming students, and promote their intellectual, social, and moral capacities by reading other people's experiences and thoughts. At an advanced stage, readers acquire reading skills, like speed, independence in reading, and the ability to fully comprehend embedded messages and meanings in the texts. Moreover, they will be able to determine the ideas of the read material, develop their intellectual wealth, gain high morals and values, and adjust their negative behaviors. Reading can also promote the ability, to think, imagine, and create. In addition, it can help the reader comprehend, criticize, and judge read material, as well as benefit from it to solve problems, exploit spare time to read, and benefit from the reading in real life. (Lafi, 2006, p. 14)

Aversion from reading can be defined, from a psychological standpoint, as "a psychological and personal state at the same time, i.e. lack of desire to read and choosing other inclinations or methods to avoid reading, like relying on electronic resources, like Internet, as a search engines. (Sayedhom, 2013, p. 250)

It seems the students' aversion from reading has turned into a social phenomenon. We won't be successful in attaching a child or student to reading unless we create means and methods to make him love reading. However, Love of reading does not come from nothing, and it won't be the result of reading a single book. Instead, this passion is born after a number of continuous readings until the child or student becomes addicted to reading.

Nowadays, the call for free reading has increased significantly, especially in this era of information revolution and knowledge. This revolution has impacted the culture of many people and has targeted youth and young minds in the first place. The existence of multimedia and modern technology is one of the most attractive means for youth due the excitement, beauty, and entertainment these means deliver. Therefore, some youth will choose to leave books on bookshelves in the libraries gathering dust as they follow TV channels, CD film, and computers. (Ghazi, p 2)

Complaints about students' dislike and disinterest of reading have increased recently. Researchers have also noticed the low number of students who practice free reading. Maybe the most prominent features of such weakness is that student show weak performance in written exams and prefer objective exams due to their poor writing skills and abilities. This means that they do not want to carefully read and study the curriculum or any other book 
their teacher chooses. Moreover, they show poor performance in report and research writing, as they prefer to rely on online resources or special libraries that prepare researches and reports for them, instead of going to libraries and reading different books.

The reasons behind the students' disinterest in free reading are various. They can be social, economic, or electronic reasons. Some or all of these reasons may have contributed to the students' aversion from reading, increasing the gap and creating a crisis. Therefore, and through this study, the main and direct reasons for the students' aversion from reading will be determined.

Researchers have conducted a number of studies related to the subject of this study.

Worthy, et al. (1999) identified the preferred reading materials and methods of obtaining them by studying sixth grade students from three middle schools. Open questions, questionnaires, and interviews with librarians were used to obtain study results, which showed that stories, horror books, comic books, caricatures, magazines on popular culture, sports books and magazines, drawings, car and truck books, and animal books were the most favorite for the study sample. Gender and economic status had no effect on the different favorite reading materials. The results showed that the majority of students received the reading material by buying from shops or from their homes instead of schools and libraries.

Al-Jarf study (2004) aimed to identify the reading interests of the female students of King Sou'd University in Riyadh in the faculties of translation, languages, and education. The study sample comprised 345 female students between 18 to 22 years old. The study revealed that $77 \%$ of students read entertainment magazines aimed at women. The percentage of topics were as follows: $77 \%$ fashion and make-up, $66 \%$ art, $24 \%$ poetry, $20 \%$ stories, $20 \%$ general health, $4 \%$ religious topics, $3 \%$ education topics, $2.5 \%$ literary topics, $2 \%$ political topics, $1.5 \%$ computer and technology, and $1 \%$ historical topics.

Qoujah study (2008) identified the activity of free reading practiced by high school students at the Republic of Yemen. The study also discovered the students' demand for reading, the areas of reading the student prefer, the obstacles that prevent students from reading, and the existence of statistically significant differences for inclination to read that can be attributed to the variables of gender and major.

A questionnaire was used on a sample composed of the male and female students of the 2nd and 3rd year of high school with the two majors (scientific and literary) in the capital Sana'a. The results showed that the students demand for reading amounted to $74 \%$, with most student leaning towards religious topics, the conduct of companions and prophets, stories and jokes, riddles and puzzles, and the stories of singers and actors (in the order). The results of the study also revealed the existence of statistically significant differences between genders in the quality of the read material students favor, while the main obstacles were that students were too busy in their studies and homework, lack of free time for reading in the school library, the density of the curriculum, helping the family with housework, the lack of a special lesson dedicated for reading in the school library.

Machet (2011) conducted a study where he compared the results of his study with the results 
of a study conducted in Roehampton institute in London (1996). The study aimed to understand the relationship between reading and attitudes toward a range of social issues. It also attempted to study the obstacles that face children and young adults as they try to read, and provide information on reading habits according to a number of variables: age, gender, background, geographical location, and educational stages, to distinguish between traditional forms of reading (publications) and new developments in text presentation and interaction (including audio tapes and the Internet). The study sample comprised students from 5th, 6th, and 7th grade in eight primary schools, and 8th, 9th, and 10th grades in five secondary schools in Gauteng County (South Africa).

The results of the study showed no difference in the reading tendencies between South African and London students, but there was a marked difference in children between the ages of 7-11 who showed a strong interest in reading religious literature in South Africa. Moreover, South African children showed little interesting in cartoons and comics compared to children of London.

Mohsen's study (2013) identified the reasons behind the aversion from university libraries among students. The study also attempted to discover whether these reasons would differ depending on the academic level and gender. The study sample comprised 160 female and male students from the basic education faculty / University of Diyali / Iraq, equally distributed among 4 departments: Educational Guidance, English Language, History, and Mathematics. The study used al-Kubaisi measure (1984) and revealed 7 reasons behind the students' aversion from libraries, four of which were for students of the first stage. The reasons include the following: some students believed that the textbooks were sufficient for success, lack of desire for some students to complete their higher studies, oral and written exam questions rely only on the course book, and some teachers do not encourage students to write reports.

Sayedhom (2013) highlighted the importance of reading in Algerian universities, identified the reasons for students' aversion from reading, and reached scientific solutions for the development of reading skills for university students.

The results of the study proved study hypotheses. In light of this, the study provided a number of recommendations, such as: improving the processes of selecting and delivering books and sources in libraries according to the students' tendencies based on field studies, opening the library all week, via a shift system and providing a reading-friendly environment.

Attiah (2013) attempted to disclose the reality of electronic reading of students / teachers of the Arabic language in Egypt and Saudi Arabia, and compare the realities of both countries. The study attempted to identify the attitudes of students / teachers of the Arabic language and their motivation towards free electronic reading, the areas of free electronic reading they are prefer, and the constraints of free electronic reading by using a questionnaire distributed to a sample of 200 students.

The results of the study showed positive attitudes of students / teachers of Arabic language toward free electronic reading in Egypt and Saudi Arabia. It also revealed the diversity, 
motivation, and constraints of free electronic reading, as well as the absence of statistically significant differences in the motives, areas, and trends of free electronic reading between Saudi and Egyptian students / teachers. However, there were statistically significant differences in the impediments to free electronic reading in favor of Egyptian students / teachers.

It is noted that the previous studies dealt with several aspects, including the sources from which the students access reading materials (the most important of which is the internet), the nature of the materials that students read, which were mostly on the recreational side (like magazines and fictional stories). Some studies focused on the reasons that lead to students' aversion from reading. This study is consistent with the objectives of the study of (Mohsen, 2013), which addressed the reasons that lead to students' aversion from reading. However, this study differed with the studies of ( Qoujah, 2008; and Worthy, 1999), which addressed the resources from which the students obtain reading material, their favorite reading material, and their reading tendencies. This study is consistent with the studies (Al-Jarf, 2004; Sayedhom, 2013) in terms of the sample of the study which was university students. Meanwhile, the current study differed with the studies of (Machet, 2001; Qoujah, 2008; and Worthy 1999), since the target group in each of these studies was school students. Moreover, the current study differed with the study of (Attiah, 2013), which focused on free electronic reading and did not address printed paper reading.

\section{Method}

\subsection{Design}

The study used a descriptive, analytical method based on information collection through a questionnaire. To achieve the objectives of the study, the following steps were taken:

Design the study tool (questionnaire) in its primary form based on theoretical literature and previous studies and their findings on the reasons that lead to students' aversion from reading. The views of a number of faculty members in Tafila Technical University were also explored, in addition to a number of university students from different specializations.

Design the two parts of the study tool: the first is related to the study sample, and the second is related to the items of the questionnaire.

Apply the study tool on 201 students studying in the second semester of the academic year $2015 / 2016$ after confirming the validity and stability of the tool.

Conduct statistical analysis to answer the study questions by calculating the arithmetical averages, the standard deviations, and the binary variance analysis test.

\subsection{Study Population}

The study population consists of (346) students of the Faculty of Educational Sciences / Tafila Technical University studying in the second semester of the academic year 2015/2016 


\subsection{Study Sample}

The study sample consisted of (201) students, i.e. (65\%) of the study population, with (53) male students and (148) female students studying in the second semester of the school year $2015 / 2016$ being randomly selected. The reason for the discrepancy in the numbers of male students to female students, is that the major "Class Teacher" comprise a majority of females. Table (1) shows the distribution of the study sample according to the variables of the study (gender and academic specialization).

Table 1. The Distribution of the Study Sample According to the Variables of the Study

\begin{tabular}{llll}
\hline Gender / Academic specialization & Males & Females & Total \\
Class teacher & 10 & 63 & 73 \\
Special education & 43 & 85 & 128 \\
Total & 53 & 147 & 201 \\
\hline
\end{tabular}

Based on the statistics of the department of Admission and Registration at Tafila Technical University for the academic year 2015/2016

\subsection{Study tool}

In order to achieve the objectives of the study, a questionnaire was developed consisting of (45) items by reference to the theoretical literature and previous studies on students' aversion from reading ( Mohsen, 2013).

\subsubsection{Validity}

The validity of the tool was verified using content validity. The tool was presented to (8) members of the teaching staff in Jordanian universities, and to educational supervisors in the Ministry of Education. The said members were requested to evaluate the appropriate degree of study tool. Afterwards, the items received an $80 \%$ appropriation level. In addition, the number of items of the tool was finalized to (45). In this study, the researchers adopted a quantitative measure, according to the Likert scale (very high, high, intermediate, few, very few), with the following values: $(5,4,3,2,1)$, respectively.

\subsubsection{Reliability}

To ensure the stability of the study tool, the sample was applied to a sample of 25 students from outside the study sample using the retest method and with a 15 days interval. Afterwards, the correlation coefficient was obtained and its value was $(0.87)$. which is suitable for the purposes of the current study.

\section{Statistical processing}

The data were processed statistically using the SPSS program, with the following statistical 
descriptive and analytical processing:

Arithmetic averages and standard deviations.

Two-Way Anova

The values of the arithmetic averages were assigned as follows:

Every item with an average of less than (2.33) will be of a low degree;

Every item with an average of $(2.34-3.67)$ will be of a medium degree;

Every item with an average of more than (3.67) will be of a high degree.

\section{Results}

The results will be presented and discussed according to the sequence of study questions, as follows:

First, the results related to the first question: What are the reasons behind aversion from free reading by the students of the faculty of educational sciences at Tafila Technical University who are studying in the second semester of the school year 2015/2016?

To answer this question, the arithmetic averages and standard deviations were calculated by the responses of study sample on each item of the study tool, as the items were arranged in descending order, as shown in Table 2.

Table 2. Arithmetic Averages, Standard Deviations, Grade, and Rating for Each Items of the Study Tool

\begin{tabular}{|c|c|c|c|c|c|}
\hline \# & Item & $\begin{array}{l}\text { Arithmetic } \\
\text { average }\end{array}$ & $\begin{array}{l}\text { Standard } \\
\text { deviations }\end{array}$ & Arrangement & Rating \\
\hline 1 & Electronic addiction by students & 4.11 & 970. & 1 & High \\
\hline 2 & $\begin{array}{l}\text { Students are inclined to accept } \\
\text { ready-made information instead of } \\
\text { searching for information }\end{array}$ & 3.72 & 1.10 & 2 & High \\
\hline 41 & $\begin{array}{l}\text { Students are satisfied with the } \\
\text { information provided by the } \\
\text { teachers }\end{array}$ & 3.53 & 1.17 & 3 & Medium \\
\hline 34 & $\begin{array}{l}\text { The scarcity of seminars and open } \\
\text { dialogues that encourage reading }\end{array}$ & 3.52 & 1.12 & 4 & Medium \\
\hline 18 & $\begin{array}{l}\text { The scientific material provided by } \\
\text { the teachers is insufficient for the }\end{array}$ & 3.51 & 1.25 & 5 & Medium \\
\hline
\end{tabular}


number of students

26 The students rely on summaries 3.50

Medium instead of main references

43 Follow TV and satellite stations 3.36

Medium excessively

32 No library at home

3 Lack of motivation to read

21 Lack of orientation from teachers 3.29 towards reading

14 Excessive use of technology

16 Scientific material is not 3.29 sufficiently available

44 The production of the book does 3.28 not encourage reading

12 The University library shows lack 3.28 of interest when it comes to educating students

39 The weak role of media in 3.26 encouraging reading

30 The social environment does not 3.24 encourage reading

35 There are no incentives for 3.22 publishing and distribution houses

19 Use the traditional methods of 3.20 teaching

5 Lack of perseverance and boredom 3.19 when reading

23 Library's lack of books and 3.19

Medium

Medium

Medium

Medium 
references

36 Absence of role models in reading 3.18

21

Medium

33 Poor reading encouragement from 3.18

1.09

22

Medium

childhood

20 Not encouraging students to 3.13

Medium research and investigate

10 Loss of the will to change by 3.12

Medium students

6 Lack of desire to read

Medium

$4 \quad$ Lack of enjoyment in reading

Medium

24 Lack of adequate financial support 3.09

Medium for the library

31 Low household income

Medium

8 The students' lack of awareness of 3.04 the importance of reading

40 Prefer reading electronically on 3.03

Medium paper reading

25 Book prices are generally high

Medium

15 The scientific material available in 2.98 the library does not meet the students' wishes

45 Lack of reading skills among 2.97

Medium students

13 Lack of scientific material for 2.97

Medium students in the library.

28 Parents do not read

Medium

11 Low critical thinking skills among 2.93

1.01

36

Medium 
students

9 Weak confidence in students

Medium

42

Increasing role of media as a 2.87

1.35

38

Medium competitor for reading

38 Intellectuals do not have enough 2.87

Medium respect from society

22 There are no printing and copying 2.83 services in the library

27 Low level of education for parents

Medium

$7 \quad$ No time to read

1.00

42

Medium

29 Parents' careers do not encourage 2.73

Medium

17 What teachers provide does not 2.70

Medium meet all the students' needs

37 Few books and magazines 2.64

Medium exhibitions

The tool as a whole

Table (2) shows that the majority of the items of the study tool obtained a medium rating in light of the study sample responses to the adopted measure. The average means ranged from $2.64-4.11$, with a standard deviation of 0.54 , which also falls within a medium rank. Item 1 "Electronic addiction" came in first by the students with an arithmetic mean of 4.11 and a standard deviation of 0.97 , followed by item 2 "Students inclination to ready-made information instead of searching for information" with an arithmetic mean of 3.72 and a standard deviation of 1.1, as both items are the only ones ranked high. Meanwhile, item 37 "Lack of magazines and books exhibitions" came in last with an arithmetic mean of 2.64 and a standard deviation of 1.22 , falling into the medium rank.

Second, the results related to the second question: Does the degree of the sample's ratings of the reasons behind aversion from free reading of the students of the faculty of educational sciences at Tafila Technical University who are studying in the second semester of the academic year 2015/2016 vary according to the study's variables: gender (male and female) and major (class teacher and special education)? 


\section{Macrothink}

Journal of Studies in Education

ISSN 2162-6952

2017, Vol. 7, No. 2

To answer this question, the arithmetic mean and standard deviations of the variables of the study: Gender (Male and female) and academic specialization (class teacher, special education), were calculated as shown in Table 3.

Table 3. Arithmetic Means and Standard Deviations of the Variables of the Study (Sex, Study Specialization)

\begin{tabular}{llll}
\hline Gender & Academic specialization & Arithmetic means & Standard deviations \\
\hline Males & Class teacher & 3.33 & 0.45 \\
& Special Education & 3.06 & 0.50 \\
& Total & 3.11 & 0.50 \\
Females & Class teacher & 3.13 & 0.56 \\
& Special Education & 3.17 & 0.54 \\
& Total & 3.15 & 0.55 \\
\hline
\end{tabular}

Table (3) shows that the items of the study variables: gender (Male and female) and academic specialization (class teacher, special education) obtained a medium rating in light of the study sample responses to the adopted measure. The average means ranged from $3.33-3.06$, with a standard deviation ranging between $0.45-0.56$. The arithmetic mean for females, which was 3.15 with a standard deviation of 0.55 , was higher than the arithmetic mean for males, which was 3.11 with a standard deviation of 0.5 . Meanwhile, the highest arithmetic mean under the study's variables was the arithmetic mean of males studying "Class teacher" with 3.33 and a standard deviation of 0.45 . On the other hand, the lowest arithmetic mean under the study's variables was the arithmetic mean of males studying "Special education" with 3.06 and a standard deviation of 0.50 .

To discover the impact of the study's variables (gender and academic specialization) on the ranking of the students' aversion from reading, Two-Way Anova test was conducted, as demonstrated in table 4. 
Table 4. Two-Way Anova test to discover the impact of the study's variables (sex and academic specialization) on the ranking of the students' aversion from reading

\begin{tabular}{|c|c|c|c|c|c|}
\hline Source & $\begin{array}{l}\text { Square } \\
\text { groups }\end{array}$ & $\begin{array}{l}\text { Degree } \\
\text { of } \\
\text { freedom }\end{array}$ & $\begin{array}{l}\text { Square } \\
\text { average }\end{array}$ & Value $(\mathrm{P})$ & Significance \\
\hline Gender & 0.060 & 1 & 0.060 & 0.205 & 0.651 \\
\hline Academic specialization & 0.361 & 1 & 0.361 & 1.229 & 0.269 \\
\hline $\begin{array}{l}\text { Interaction between sex } \\
\text { and } \\
\text { specialization }\end{array}$ & 0.594 & 1 & 0.594 & 2.022 & 0.157 \\
\hline Error & 57.836 & 197 & 0.294 & & \\
\hline Total & 2049.465 & 201 & & & \\
\hline Corrected total & 58.506 & 200 & & & \\
\hline
\end{tabular}

Table (4) shows that there are no statistically significant differences at the level of significance $(\alpha<0.05)$ in the students' ranking of the reasons (that lead to aversion from reading) which can be attributed to the gender variable (male and female), with a value of (0.205), which is not statistically significant.

There are also no statistically significant differences for the variable of specialization (special education and class teacher), since the value of $(\mathrm{P})$ amounted to (1.229), while the value of $(\mathrm{P})$ of the interaction of gender and the specialization amounted to (2.022), which is not statistically significant at the level of significance.

\section{Discussion}

Discussion of the results related to the first question: What are the reasons behind aversion from free reading by the students of the faculty of educational sciences at Tafila Technical University who are studying in the second semester of the school year 2015/2016?

The results showed that the most important reason that leads to aversion from reading is electronic addiction by the students. This result can be interpreted by taking into consideration the knowledge explosion the world witness, the provision of means of modern technology that are widely varied. These tools have become available to everyone, whether computer hardware or mobile phone. Telecommunications companies are competing to provide permanent internet services at low cost. This result conforms to the result of (Sayedhom, 2013) study, which stated that the spread of modern technology in different types contributed to the students' aversion from reading. Such spread has led to the increasing gap 
between the university student and traditional libraries.

The other reason that leads the students of the Faculty of Educational Sciences to avert from reading is the tendency of students to accept and want ready-made information instead of searching for it. This result may be explained by the fact that students in schools and universities are used to the traditional way of teaching that depends on the teacher in providing information, without a need for the students to read and browse sources and references. Moreover, the students' reliance on the curriculum has contributed to the students' tendency to accept and receive ready-made information. The result of the study agrees with the results of (Mohsen, 2013) that revealed students' belief that textbooks are sufficient for success, relying on the oral, written, and editorial exam questions based solely on the course book.

As for the results related to the second question: Does the degree of the sample's ratings of the reasons behind aversion from free reading of the students of the faculty of educational sciences at Tafila Technical University who are studying in the second semester of the academic year 2015/2016 vary according to the study's variables: gender (male and female) and major (class teacher and special education)?There were no statistically significant differences that can be attributed to the study's variables - gender and academic specialization. This result contradicted the results of ( Mohsen 2013), and (Qoujah 2008) which detected differences in the reading and reading tendencies rations related to gender and specialization.

The item "Lack of book and magazine exhibitions" can be explained by the keenness of schools and universities to hold books and magazines exhibitions constantly, so that adults and young people can buy various books with the lowest prices to encourage the acquisition and reading of books. This can be easily observed in the cooperation of the Ministry of Education with the Family Library, where each year (4000-5000) comprehensive and different books are provided.

\section{Recommendations}

In light of these findings, the study recommends the following:

- Encourage faculty members to read, improve the quality of scientific material provided by to students, and include at least a question from the self-reading references, and increase the sources and references for each subject, which can be called self-reading references.

- Raise the students' awareness of the importance of reading and its benefits by conducting seminars and dialogues to encourage reading.

- Use new methods of teaching and do not emphasis on indoctrination, in order to encourage students to read continuously.

- Provide continuous material and moral assistance to the university library;

- Provide family education to increase the desire to read. 


\section{Conclusion}

The study concluded that main reasons behind aversion from reading by the students were electronic addiction and students' tendencies towards having the information which is easy to reach instead of looking for it.

\section{References}

Abdul Bari, M, Sh. (2009). Sociology of Reading and its Educational Applications. Amman: Dar Al-Masyra for Publishing.

Adas, M. (2005). Role of Reading in Development of Thought. Amman: Dar Al Fikr for Publishing.

Attiah, M, A. (2013). The reality of free electronic reading among students who are Arabic language teachers in Egypt and Saudi Arabia, Journal of Educational Sciences, 25(2), 357-389

Awartani, S, T. et al. (2009). Introduction to Reading Difficulties. Amman: Dar Wael for Publishing.

Ghazi, Watheq. The youth's aversion from reading: reasons, results, methods of treatment. www.geologyofmesopotamia.com/library/youngs2.pdf, retrieved in 5/2/2016.

Al-Jarf, R, S. (2004). What does our youth read in the era of globalization? Research presented to Globalization and the Priorities of Education seminar, College of Education King Saud University - Education.

Lafi, Sa'eed Abdullah (2006). Reading and Development of Thought. Amman: World of Books for Publishing.

Machet, M.P. (2001) Young people's reading interests in South Africa. ERIC NO .ED 455505

Mohsin, M, A. (2013). Reasons for the lack of interest of some university students to visit libraries. Al-Fath Journal, 1(53), 53-69.

Qoujah, K, I. (2008). Evaluation of Free Reading Activity among Secondary School Students in the Republic of Yemen, unpublished Master Thesis. Sana'a University, Yemen.

Saad, M, A. (2006). Weak Reading and Methods of Learning (Theory, Research, Training and Testing). Dar Al-Wafa Printing and Publishing House.

Sayedhom, Kh, H. (2013). The reasons behind students' aversion from reading and the methods to develop their reading skills: Field study for third year students of Licentiate, Library Science and Documentation Sciences, University of Batna. Algeria, 1(12), 37-45.

Worthy, Jo, Moorman, Megan, \& Turner, Margo (1999). What Johnny Likes to Read Hard to Find in School. Reading Research Quarterly, 34(1), 12-27. https://doi.org/10.1598/RRQ.34.1.2 